\title{
Agenda e coalizões na aprovação de uma Política Pública Inovadora: o caso da Lei de Conformidade Tributária de São Paulo
}

\section{Agenda and coalitions in the approval of an Innovative Public Policy: the case of São Paulo Tax Compliance Law}

\author{
Humberto Eustáquio César Mota Filho \\ Centro Brasileiro de Estudos e Pesquisas sobre a Democracia (CEBRAD/UERJ) \\ E-mail: humberto@bndes.gov.br
}

Eduardo Almeida Mota

Secretaria da Fazenda e Planejamento do Estado de São Paulo (SEFAZ/SP)

Columbia University - NY

E-mail: eam2233@columbia.edu

Luciano Quinto Lanz

Banco Nacional do Desenvolvimento Econômico e Social (BNDES)

Columbia University - NY

E-mail: lqlanz@hotmail.com

Resumo: Políticas públicas inovadoras usualmente enfrentam resistências à sua implementação, por contrariarem interesses de segmentos com capacidade de mobilização, especialmente quando há dependência de aprovação legislativa. Este artigo analisa o processo de aprovação da Lei Complementar 1.320/2018 pela Assembleia Legislativa de São Paulo, que instituiu o Programa de Estímulo à Conformidade Tributária - "Nos Conformes". O programa é polêmico ao estabelecer regras de conformidade tributária e criar uma classificação ostensiva de risco de contribuintes. A metodologia utilizada é o estudo de caso único, com análise de dados secundários, como publicações na imprensa, portais especializados e ações da SEFAZ. Para análise é utilizada a literatura sobre agenda setting e, sobre participação social, além do papel despenhado pelas burocracias e legislaturas em inovações legislativas. Os resultados indicam que a SEFAZ conseguiu formar uma coalização, por meio do diálogo e da criação de confiança entre entidades empresariais, instituições políticas, sociedade civil e entidades representativas dos fiscais, levando à aprovação de um programa significativamente melhorado em relação à proposta original em um curto espaço de tempo. O estudo permite construir um quadro de referência para o avanço de agendas e formação de coalizões para aprovação de propostas legislativas.

Palavras-Chave: Conformidade Tributária; Agenda Legislativa; Políticas Públicas. 
MOTA FILHO, Humberto Eustáquio César; MOTA, Eduardo Almeida; LANZ, Luciano Quinto. Agenda e coalizões na aprovação de uma Política Pública Inovadora: o caso da Lei de Conformidade Tributária de São Paulo.

Abstract: Innovative public policies usually face resistance to their implementation, because they contradict the interests from segments with mobilization capacity, especially when there is legislative approval dependence. This article analyzes the approval process of Complementary Law 1,320 / 2018 by the Legislative Assembly of São Paulo, which instituted the Program for Stimulating Tax Conformity - "Nos Conformes". The program is controversial in establishing tax compliance rules and creating an outward classification of taxpayer risk. The methodology used is the single case study, with analysis of secondary data, such as publications in the press, specialized portals and actions of SEFAZ. For analysis, the literature on agenda setting and social participation is used, as well as the role played by bureaucracies and legislatures in legislative innovations. The results indicate that SEFAZ was able to form a coalition, through dialogue and the creation of trust between business entities, political institutions, civil society and representative entities of the inspectors, which led to the approval of a significantly improved program compared to original proposal in a relatively short space of time. The study builds a framework that can be used to advance agendas and build coalitions for legislative proposal approval.

Keywords: Tax Compliance; Legislative Agenda; Public Policy.

\section{Introdução}

Políticas públicas inovadoras usualmente enfrentam resistências para sua implementação, especialmente em casos em que essas inovações podem contrariar interesses estabelecidos, afetar determinados segmentos econômicos e sociais, com capacidade de mobilização ou dependam de trâmites legislativos. A agenda tributária é um dos campos onde seu desenvolvimento e evolução tem sido particularmente difíceis. As discussões sobre reforma tributária apesar de recorrentes pouco avançam. Este artigo tem a proposta de analisar o processo de construção das condições que levaram à aprovação de uma nova legislação tributária em São Paulo neste contexto.

Os resultados iniciais da análise indicam que a aprovação da Lei Complementar $n^{\circ}$ 1.320/2018 (“Lei”) pela Assembleia Legislativa do Estado de São Paulo (ALESP) contendo inovações como temas da agenda de compliance tributário, só foi possível graças à atuação de empreendedores legislativos localizados na própria Administração Pública que mobilizaram apoiadores da sociedade civil ao proverem os incentivos corretos para os diferentes atores envolvidos e criarem um ambiente de confiança.

Revista Brasileira de Políticas Públicas e Internacionais, v.4, n.1, julho/2019, pp. 195-219. 
MOTA FILHO, Humberto Eustáquio César; MOTA, Eduardo Almeida; LANZ, Luciano Quinto. Agenda e coalizões na aprovação de uma Política Pública Inovadora: o caso da Lei de Conformidade Tributária de São Paulo.

Para enquadrar a discussão do artigo, em marcos explicativos mais gerais, coube buscar referências teóricas na literatura de agenda setting (Kingdon, 2011) e sobre participação social (Fung, Wright, 2003; Arnstein, 1969), além do papel desempenhado pelas burocracias e pelas legislaturas (Shepsle, 2010) em propostas legislativas.

A discussão desses marcos teóricos permite esquematizar como o Compliance Tributário foi introduzido na agenda legislativa paulista e como os empresários e os gestores públicos se inter-relacionaram para avançar essa agenda inovadora, apesar dos custos de coordenação, dos interesses de cada grupo e das restrições político-burocráticas. Permite ainda, robustecer o entendimento sobre esse caso ao analisar a partir dessas expectativas teóricas como as publicações da grande impressa, sites especializados e as instituições e entidades envolvidas se pronunciaram sobre o Projeto.

Tendo em conta esse quadro esquemático, e a devida análise qualitativa, espera-se reforçar o conhecimento sobre: as estratégias utilizadas para fazer avançar a agenda de compliance tributário; a efetividade dessas estratégias; e, eventualmente, as possíveis condições de reprodução dessas estratégias para outras inovações legislativas no campo do compliance.

Esse artigo está dividido em seis capítulos, incluindo esta introdução. No segundo segmento, são abordados os conceitos teóricos para a explicação do surgimento e prevalência de agendas públicas e uma hipótese de trabalho para a compreensão do caso de sucesso da agenda de compliance no encaminhamento e aprovação da Lei, que instituiu a figura inovadora no Brasil da classificação de risco tributário dos contribuintes com tratamento positivo diferenciado para os "Bons Contribuintes". Na terceira parte, temos a descrição do caso objeto do estudo com detalhamento da metodologia adotada. No quarto capítulo, são analisados artigos técnicos em sites especializados, pronunciamentos da Administração Pública e de entidades empresariais sobre o projeto de lei, além da agenda de eventos de divulgação e discussão do projeto, segregando-se as avaliações positivas e negativas e computando-se as avaliações positivas como sendo partes da coalização de apoio ao projeto de lei. No quinto segmento temos a análise e discussão dos resultados e a busca de generalização dos achados para um quadro que possa ser replicado a outras políticas públicas. Nas conclusões, temos um resumo dos achados do artigo, de suas proposições teóricas e quadro de referência a ser

Revista Brasileira de Políticas Públicas e Internacionais, v.4, n.1, julho/2019, pp. 195-219. 
MOTA FILHO, Humberto Eustáquio César; MOTA, Eduardo Almeida; LANZ, Luciano Quinto. Agenda e coalizões na aprovação de uma Política Pública Inovadora: o caso da Lei de Conformidade Tributária de São Paulo.

utilizado para criação de agendas e criação de coalizões em contextos semelhantes e indicação de tópicos para aprofundamento e pesquisas futuras.

\section{Agendas, Interesses e Coalizões}

É possível afirmar que um determinado problema é incorporado à agenda pública quando é identificado como passível de se converter em política pública. Saravia (2006) identifica a agenda como o primeiro passo para implementação de uma política pública, a partir desta definição temos a elaboração, a formulação, implementação, execução, acompanhamento e avaliação.

O processo de formação de agenda não é estritamente técnico, dado que a identificação do problema e a formação da agenda envolvem valores, interesses, posicionamentos ideológicos e projetos políticos. A formação da agenda reflete as relações de poder entre os atores sociais envolvidos. Por isso, a agenda pode ser entendida como um indicador da priorização de temas e problemas a serem enfrentados por um governo, conforme Roth Deubel (2006) e, ao mesmo tempo, é o espaço em disputa entre os diversos atores sociais no jogo político. Pela análise da agenda é possível mapear a arquitetura de poder em dada sociedade e os temas politicamente relevantes naquele período histórico.

Como explicar então que determinados assuntos ou agendas surgem e são aprovadas com rapidez pelas casas legislativas, enquanto outras agendas permanecem emperradas nas Comissões de Constitucionalidade e Justiça ou mesmo são arquivadas, apesar do apelo ou mobilização popular que possam despertar? É bastante revelador das dificuldades de compreensão dessas questões, o exemplo da derrota da campanha das Diretas Já para Presidente em 1984 no Brasil, movimento extremamente popular a época da redemocratização e, por sua vez, dos casos escassos na agenda legislativa brasileira de propostas de redução de tributos, apesar da provável popularidade dessa agenda.

A literatura da ciência política já propôs algumas explicações, ao teorizar sobre como determinados formadores de agenda ("agenda setters") ou de políticas públicas ("policy markers") são capazes de fazer avançar agendas enquanto outras bandeiras relevantes e igualmente, ou mais populares, são relegadas ao segundo plano, em democracias modernas.

Revista Brasileira de Políticas Públicas e Internacionais, v.4, n.1, julho/2019, pp. 195-219. 
MOTA FILHO, Humberto Eustáquio César; MOTA, Eduardo Almeida; LANZ, Luciano Quinto. Agenda e coalizões na aprovação de uma Política Pública Inovadora: o caso da Lei de Conformidade Tributária de São Paulo.

Esse plano explicativo mira na importância dos defensores de determinadas iniciativas legislativas e na sua capacidade de convencimento e credibilidade (Kingdon, 2011, p. 21), destacando como causa determinante da emergência da agenda e da sua eventual aprovação a habilidade e o conhecimento técnico desses empreendedores. Como exemplo, temos o caso emblemático dos sanitaristas brasileiros que emplacaram, em grande medida, as propostas que culminaram na criação do Sistema Único de Saúde (SUS), contra o lobby poderoso das empresas e seguradoras de saúde privada. Os críticos dessa corrente explicativa apontam que ainda que os empreendedores exerçam um papel importante, eles não poderiam superar, per se, todas as resistências e resolver todas as complexidades presentes no processo legislativo e, portanto, seria preciso considerar a sociedade e as instituições políticas como fatores relevantes na formação da agenda (Windhoff-Héritier, 1991, p. 27-52).

Então, ao considerar a sociedade, é pertinente indagar qual é o papel da participação social nas agendas públicas, uma vez que essa participação pode embutir desde simples rituais chancelatórios de agendas alheias até uma participação efetiva na produção de uma agenda mais plural (Fung e Wright, 2003, p.5-6. Arnstein, 1969, p. 217). E, por sua vez, ao considerar as instituições é preciso investigar sua relevância na manutenção ou na inovação do status quo (TSEBELIS, 2002, p. 17-18) e até que ponto os atores institucionais têm importância como agenda setter (Kingdon, 2011, p. 45).

Outra vertente concentra o peso explicativo do avanço de agendas legislativas sobre a capacidade de os atores formarem coalizões de interesses vitoriosas. Nessa ótica, está embutida a relevância em angariar apoios de grupos de uma mesma classe, categoria funcional ou partido político, muitos deles reunidos em think tanks. Assim, a indústria de armas dos Estados Unidos tem o conhecido lobby da NRA - Associação Nacional dos Rifles, que também conta com apoio de grande parte da sociedade norte-americana e explica como a agenda de restrição ou proibição de venda de armas nos EUA pouco avança apesar dos repetidos episódios de tiroteios e violência nas escolas e da crescente mobilização de alunos em favor de uma agenda antiarmas.

Entretanto, a explicação do fortalecimento de agendas pela formação de coalizões, esquematiza as classes de forma estática e não responde como algumas mudanças legislativas

Revista Brasileira de Políticas Públicas e Internacionais, v.4, n.1, julho/2019, pp. 195-219. 
MOTA FILHO, Humberto Eustáquio César; MOTA, Eduardo Almeida; LANZ, Luciano Quinto. Agenda e coalizões na aprovação de uma Política Pública Inovadora: o caso da Lei de Conformidade Tributária de São Paulo.

ocorrem apesar da posição contrária das classes dominantes, de coalizões entre classes, categorias ou interesses, a priori, divergentes e como se dão importantes inovações legislativas, apesar de fortes coalizões de interesses contrárias (Nunes, 1997, p. 54).

Também é possível compreender o sucesso de determinadas agendas pela perspectiva da interação entre ideias, interesses e informações (Milner, 1997, p. 33). Assim, o exame das relações dos atores governamentais e privados permitiria explicar quando e como ocorrem mudanças nas agendas, em virtude de mudanças nas preferências desses atores, tendo em conta os cenários doméstico, internacional e as instituições. Essa abordagem explica mudanças na formação e na escolha de agendas públicas e foi aplicada com sucesso em casos de políticas de comércio exterior (Mota Filho, 2016).

Ultimamente, tem-se atribuído mais peso ao papel das redes, das comunidades e dos subsistemas na análise de políticas públicas. As redes temáticas são caracterizadas por: existência de muitos participantes; interação e acesso flutuantes para os vários membros; ausência de consenso e presença de conflitos; interação com base em consultas em vez de negociação ou barganha; uma relação desigual de poder em que muitos participantes podem ter poucos recursos, pouco acesso e nenhuma alternativa.

As Comunidades de políticas públicas (policy communities) são grupos de participação limitada, alta integração entre os membros, consistência ao longo do tempo, controle de recursos e distribuição balanceada de poder (Rhodes, 2008). Subsistema pode ser entendido como o padrão de interações entre o conjunto restrito de participantes envolvidos na tomada de decisões em uma área específica das políticas públicas (Freeman, 1955, p. 265). Por meio do conceito de subsistema seria possível observar padrões de interação existentes entre pessoaschave do Executivo, líderes de comissões do Congresso e outros atores, especialmente grupos de interesse. Em outras palavras, o conceito de subsistemas se refere às instituições sociais e à forma como elas interagem umas com as outras e com entidades e atores não governamentais (Capella, Brasil, 2015, p. 58-59).

Contudo, para a formação de coalizões, para a interação em comunidades ou em redes, é preciso um ambiente de cooperação e confiança. No entanto, boa parte dos brasileiros tem dificuldades no estabelecimento de relações de confiança entre estranhos. A grande maioria

Revista Brasileira de Políticas Públicas e Internacionais, v.4, n.1, julho/2019, pp. 195-219. 
MOTA FILHO, Humberto Eustáquio César; MOTA, Eduardo Almeida; LANZ, Luciano Quinto. Agenda e coalizões na aprovação de uma Política Pública Inovadora: o caso da Lei de Conformidade Tributária de São Paulo.

acredita que a outra parte quer tirar vantagem na relação (CNI, 2017, p. 1-3). Mesmo as empresas brasileiras consideradas inovadoras colaboram menos com outras organizações nacionais ou internacionais do que as empresas de grande parte dos países da OECD (Ovanessoff, Plastino, Faleiro, 2015, p. 4).

Essas lacunas na confiança social comprometem a colaboração nas relações comerciais. Nas relações público-privadas, ou fisco-contribuinte não há razão para supor que o quadro é melhor. Nesse cenário, é forçoso investigar se o caso da Lei "Nos Conformes" realmente trouxe uma forma de cooperação baseada na criação de laços de confiança e como isto foi possível, num curto espaço de tempo.

No campo teórico do estudo da cooperação entre indivíduos ou organizações, explica-se a colaboração entre diferentes atores com base em processos evolutivos de interação. Pela Teoria da Cooperação (Axelrod, 1984, p. 172-174), defende-se que para a continuidade de uma cooperação é preciso que as partes atuantes sejam capazes de se reconhecer e de recordar das suas interações prévias e que os casos de interação bem-sucedidos tendem a ser copiados ou serem mais frequentes dali em diante, sugerindo a existência de mecanismo próprio para uma interação exitosa, mas mesmo assim, seria possível mais de uma estratégia para incentivar a colaboração social.

Para investigar se realmente houve uma estratégia da Secretaria da Fazenda do Estado de São Paulo (SEFAZ/SP) no sentido de criar ou reforçar laços de confiança no subsistema de compliance tributário, existem modelos de fluxos de aprovação de políticas públicas que tomam esses conceitos como base, embora analisem de forma distinta suas influências na formação e aprovação das agendas (Kingdon, 2011; True, Baumgartner, Jones, 1999; Sabatier, Jenkins Smith, 1993).

Tais modelos destacam o papel das ideias e dos interesses nos subsistemas, desenvolvendo conceitos complementares em cada caso, entretanto não avançam tanto na busca de respostas para o problema da confiança. No caso brasileiro, é recomendável avançar na compreensão do padrão de interação entre o conjunto de participantes de um subsistema de políticas públicas, para então progredir na análise das interações entre subsistemas relacionados (Capella, Brasil, 2015). Uma oportunidade de fazê-lo é a análise das interações entre os

Revista Brasileira de Políticas Públicas e Internacionais, v.4, n.1, julho/2019, pp. 195-219. 
MOTA FILHO, Humberto Eustáquio César; MOTA, Eduardo Almeida; LANZ, Luciano Quinto. Agenda e coalizões na aprovação de uma Política Pública Inovadora: o caso da Lei de Conformidade Tributária de São Paulo.

membros do subsistema do compliance tributário, a fim de permitir futuras análises entre outros subsistemas de compliance entre si. Para tanto, é preciso introduzir antes a agenda do sistema geral de compliance, a agenda específica do compliance tributário, discutida no caso da Lei "Nos Conformes" e desenvolver conceitos auxiliares para os modelos existentes no endereçamento do problema da confiança.

Para os propósitos desse artigo, utiliza-se o conceito de formadores de agenda de Kingdon ("agenda setters") ou formuladores de políticas públicas ("policy markers") capazes de fazer avançar agendas públicas, como é o caso das propostas presentes na Lei "Nos Conformes", mas não se presume como dado o grau de coesão da comunidade ("subsistema") de compliance tributário do Estado de São Paulo. Aqui, o que se quer investigar é exatamente como se deu a dinâmica de interação entre essa comunidade e quais foram os fatores que permitiram a cooperação de diferentes atores, culminando com a aprovação de um texto legal inovador, a fim de contribuir para o aperfeiçoamento das explicações sobre como se dá o fluxo de formulação de uma política pública (Saravia, 2006, p. 32-34).

Assim, busca-se compreender como a estratégia adotada pela SEFAZ/SP, na qualidade de agenda setter, estimulou a cooperação dos atores públicos e privados e influenciou positivamente o fluxo de políticas públicas. Em outras palavras, pretende-se verificar qual o impacto dessa estratégia sobre o envolvimento e a participação efetiva dos stakeholders nas discussões sobre a agenda de compliance tributário, dado o problema de confiança.

\subsection{Em busca da conformidade: a Agenda de Compliance Tributário}

A Agenda de compliance ("Agenda") segue a tendência de, além do uso de mecanismos de controle para identificação e prevenção de desvios, criar benefícios e estímulos de boas condutas voltados para a implementação de uma cultura de transparência e integridade nos setores públicos e privados. Parece haver certo consenso sobre quais são as melhores práticas e técnicas para a implementação dessa Agenda no mundo dos negócios corporativos (IBGC, 2017, p. 9-11). Em termos gerais, ser capaz de prevenir, detectar e responder a desvios e riscos éticos e legais, estejam eles presentes no setor público, no setor privado e, principalmente, na interação entre os setores público e privado. Vários estudos, tais como Alm, Martinez-Vazquez

Revista Brasileira de Políticas Públicas e Internacionais, v.4, n.1, julho/2019, pp. 195-219. 
MOTA FILHO, Humberto Eustáquio César; MOTA, Eduardo Almeida; LANZ, Luciano Quinto. Agenda e coalizões na aprovação de uma Política Pública Inovadora: o caso da Lei de Conformidade Tributária de São Paulo.

e Torgler (2010), Bird (2010), FMI (2016), indicam que este sistema pode ser mais eficiente se além de controles, recorrer a mecanismos de alinhamento de interesses e criação de um ambiente de confiança e colaboração entre as partes, que desestimule comportamentos oportunistas e recompense as boas práticas. Então, é possível pensar num sistema de compliance, com diretrizes gerais extensíveis ao setor público e ao setor privado.

Um sistema de compliance apresenta um componente próprio comportamental e jurídico, dado que a essência do compliance envolve uma deliberação permanente sobre como definir o que são desvios e riscos éticos e como interpretar juridicamente as prescrições legais, após sua definição. Por sua vez, a própria caracterização de desvios éticos e riscos jurídicos se transforma ao longo do tempo. Tudo isso confere uma grande abrangência a essa agenda. Mas, além disso, essa agenda permite, pelo seu componente ético, uma grande permeabilidade com os mais variados temas de políticas públicas e uma transversalidade com uma grande gama de assuntos de apelo social, econômico e político.

Nesse sentido, poder-se-ia compreender que todas as políticas públicas necessitariam passar pelo crivo ou pela ótica do compliance, pois o desenho de toda política pública traz em si um elemento de risco, uma escolha entre alternativas comportamentais possíveis, o que implica necessariamente uma análise valorativa e um potencial de desvios éticos. Até aqui, parece que a agenda de compliance tem se concentrado mais nos desvios e riscos potenciais do relacionamento entre os atores públicos e privados (Catlett, Saud, 2016, p. 4).

No caso da Lei "Nos Conformes", o foco maior da agenda concentra-se no campo das questões tributárias, dado o seu direcionamento para o tratamento do relacionamento entre contribuintes e o fisco, no Estado de São Paulo. Portanto, nesse campo, a agenda deve endereçar formas de prevenir, detectar e responder a desvios e riscos éticos e legais na relação fisco e contribuinte. Da mesma forma como não há uma única receita ou agenda de compliance tributário, também não se pode falar em uma única forma de fazer avançar as propostas de agendas legislativas. Ao que parece, no caso da Lei "Nos Conformes" houve uma inovação na forma de debate da agenda e na construção de apoios para fazer avançar essa agenda.

Revista Brasileira de Políticas Públicas e Internacionais, v.4, n.1, julho/2019, pp. 195-219. 
MOTA FILHO, Humberto Eustáquio César; MOTA, Eduardo Almeida; LANZ, Luciano Quinto. Agenda e coalizões na aprovação de uma Política Pública Inovadora: o caso da Lei de Conformidade Tributária de São Paulo.

\subsection{Uma hipótese para o avanço da Lei Complementar $n^{\circ} 1.320 / 18$}

Para a investigação do caso, é preciso entender as estratégias adotadas pelos policy makers e pelos agenda setters atuantes nesse setor (Menzel, 2005, p. 151), as quais permitiram que as instituiçõos brasileiras desenvolvessem nos últimos tempos um conjunto de leis substanciais destinados ao aperfeiçoamento de uma cultura da integridade e da transparência entre os setores públicos e privados ${ }^{1}$.

Desse modo, busca-se investigar como foi possível, angariar apoio social e institucional para alçar essas iniciativas ao status de um Projeto de Lei Complementar e, posteriormente, como se deu a aprovação dessa agenda positiva de compliance tributário, num momento de restrições fiscais severas em todas as unidades da federação brasileira.

Assim, para os propósitos de um artigo sobre a construção de coalizões políticas em temas de compliance, é válido examinar como a proposta de classificação de risco dos contribuintes com base na medição objetiva de critérios de conformidade, consubstanciada no Projeto de Lei Complementar $n^{\circ}$ 025/2017, foi aprovada pela ALESP em 03/04/2018. A aprovação do Projeto pode sugerir que a iniciativa não sofreu grande resistência parlamentar, não teve opositores na sociedade civil ou na burocracia pública. Entretanto, é preciso verificar se a iniciativa legislativa realmente estava isenta de resistências e, em caso negativo, como foram angariados apoios e contornadas as eventuais resistências.

Pela lógica do agente racional e seus interesses (Shepsle, 2010, p. 410), a burocracia estatal tende a buscar a maximização dos seus recursos orçamentários em suas propostas sobre questões técnicas como as normas tributarias e fiscais. Já na lógica dos interesses especiais das associações empresárias, os empresários tendem a apoiar propostas que privilegiam a diminuição da carga tributária, concedam benefícios setoriais ou ao menos não impliquem aumento de impostos (Olson, 1965, p, 162).

\footnotetext{
${ }^{1}$ No Brasil, a implementação da agenda de compliance se deu de forma mais intensa após a edição da Lei $\mathrm{n}^{\circ}$ 12.846/13, que trata da responsabilização administrativa e civil de pessoas jurídicas pela prática de atos contra a administração pública. Além da Lei 12.846 e à exceção do Código Penal, os principais diplomas legais que versam sobre o tema de corrupção e de atos lesivos à administração pública foram promulgados, em sua maioria, mais recentemente, são eles: a Lei de Improbidade Administrativa; a Lei de Licitações; Tratados e Convenções Internacionais introduzidos em nosso ordenamento por meio de decretos legislativos (Catlett, Saud, 2016).
}

Revista Brasileira de Políticas Públicas e Internacionais, v.4, n.1, julho/2019, pp. 195-219. 
MOTA FILHO, Humberto Eustáquio César; MOTA, Eduardo Almeida; LANZ, Luciano Quinto. Agenda e coalizões na aprovação de uma Política Pública Inovadora: o caso da Lei de Conformidade Tributária de São Paulo.

É relevante notar que essa proposta legislativa, foge do padrão usual da agenda de projetos fiscais que ora procuram avançar onerações tributárias e obrigações dos contribuintes e ora investem em desonerações fiscais ou perdões e parcelamentos de dívidas. Nesse caso, há indicativos que apontam para o estabelecimento de uma cooperação entre o setor público e o privado em um curto espaço de tempo (Garcia-Zamor 2003; Rego, Sarrico, Moreira 2005; Saarniit 2005; Kim, 2011). Nesse sentido, torna-se ainda mais importante saber como se deu a tramitação desse projeto e como foram estabelecidos os apoios e realizadas as negociações para sua aprovação.

Sugere-se, neste artigo, que a aprovação da Lei pela ALESP contendo inovações legislativas foi possível graças à atuação de empreendedores legislativos localizados na própria burocracia estatal que mobilizaram apoiadores ao proverem os incentivos corretos para os diferentes atores envolvidos, criando laços de confiança entre esses stakeholders, durante a discussão das propostas.

\section{O Caso da Lei "Nos Conformes"}

Este artigo pode ser classificado como um estudo de caso único (Yin, 2014), conduzido junto à SEFAZ/SP e a seus stakeholders, em São Paulo. Para análise do caso, a primeira etapa foi a análise dos registros gerados com a tramitação inicial da proposta de criação da Lei entre os stakeholders e uma segunda etapa constituiu em uma pesquisa documental, na imprensa escrita e principais sites especializados na área tributária e de políticas públicas.

O método de estudo de caso demonstra ser adequado por fornecer mais informações dos atores e do contexto sob os quais foram realizadas as escolhas políticas que conduziram a aprovação da agenda pública de compliance tributária contida na Lei Complementar $\mathrm{n}^{\circ}$ 1.320/2018 e assim permitir testar a hipótese aqui levantada para o avanço dessa agenda. Tal método consiste no estudo de determinados indivíduos, grupos, problemas ou instituições que apresentam características próprias. Os procedimentos metodológicos buscam delimitar as suas unidades analíticas nas relações externas; relações internas e especificidades do caso. Desse

Revista Brasileira de Políticas Públicas e Internacionais, v.4, n.1, julho/2019, pp. 195-219. 
MOTA FILHO, Humberto Eustáquio César; MOTA, Eduardo Almeida; LANZ, Luciano Quinto. Agenda e coalizões na aprovação de uma Política Pública Inovadora: o caso da Lei de Conformidade Tributária de São Paulo.

modo, a análise de dados se dá frente ao quadro geral do caso em questão e é elaborada com técnicas qualitativas de pesquisa (Yin, 2014).

É importante articular o referencial teórico adotado e os dados coletados, o ordenamento dos fatos, a explicação da lógica interna ou do mecanismo interno de funcionamento do fenômeno observado e a sua articulação com outros fatos.

Os marcos teóricos unidos pela lógica do agente racional contribuíram para investigar se o caso da Lei "Nos Conformes" confirma a iniciativa da burocracia fazendária paulista como determinante no processo de negociação e aprovação de uma agenda legislativa inovadora, nos moldes de um verdadeiro agenda setter.

A articulação desses interesses e a verificação dessas tendências teóricas foi investigada, no caso concreto, a partir dos marcos temporais e espaciais registrados desse caso, sobretudo com base nas ações e propostas efetivamente realizadas e incorporadas ao texto final da Lei. Essa observação foi reforçada pela análise qualitativa dos dados constantes das propostas formalizadas nas diversas reuniões, palestras, simpósios, apresentações e consultas públicas sobre o projeto.

A fim de corroborar ou não a análise dos registros, uma segunda etapa de estudo do caso consistiu da análise de portais especializados: Consultor Jurídico, Jota, Carta Forense. Esta etapa da pesquisa foi desenvolvida no período de julho de 2017 a abril de 2018.

A confirmação da burocracia fazendária como agenda setter, significa dizer que ela foi relevante, para a modificação dos status quo legal nas relações fisco contribuinte no Estado de São Paulo, via aprovação do texto legal. Para dimensionar essa relevância, entretanto, será preciso contrapor o papel efetivo dos atores sociais. Caso haja a comprovação de interações repetidas entre os atores envolvidos no período considerado, com a incorporação de propostas advindas da maioria dos participantes é factível considerar que foram efetivamente formados laços de confiança durante esse período de debate. Daí, também é correto concluir que as estratégias adotadas pela SEFAZ/SP tornaram possível não só uma participação efetiva dos stakeholders, mas também permitiram a formação de um ambiente de confiança propício a essa participação e a uma cooperação efetiva.

Revista Brasileira de Políticas Públicas e Internacionais, v.4, n.1, julho/2019, pp. 195-219. 
MOTA FILHO, Humberto Eustáquio César; MOTA, Eduardo Almeida; LANZ, Luciano Quinto. Agenda e coalizões na aprovação de uma Política Pública Inovadora: o caso da Lei de Conformidade Tributária de São Paulo.

A análise de casos não se presta exclusivamente a produção de thick descriptions ou para produzir etnografias detalhadas da realidade social e política, essa análise serve para fazer avançar o conhecimento e suprir lacunas de estudos anteriores e para observar o grau de relação não espúria numa determinada teoria. Nesse sentido, a conexão entre casos e teorias torna-se mais frequente e aconselhável para a geração de explicações (Elman, 2005, p. 294). Adicionalmente, o estudo de caso pode levar a elaboração de novas proposições ou hipóteses, a serem testadas em outros casos e, podem confirmar, reforçar ou contestar teorias existentes ao fornecerem "testes" cruciais, ao possibilitar a extensão de explicações teóricas, explicações sobre desenvolvimentos anômalos ou desviantes, em comparações entre casos similares.

\section{Estudando o Caso: Em busca do Modelo}

O marco inicial do estudo de caso remonta a primeira apresentação oficial das linhas gerais do projeto em janeiro de 2017, apenas no âmbito da SEFAZ/SP. Nos seis meses subsequentes, de fevereiro a julho de 2017, foram realizadas diversas reuniões, palestras, simpósios e apresentações sobre o projeto tendo como ponto de partida a FIESP e o Instituto de Direito Público de São Paulo - IDP, em um movimento crescente de apoio da sociedade civil. Foram registradas, mesmo antes da elaboração da primeira minuta do projeto de lei, propostas de aprimoramentos do Centro de Cidadania Fiscal - CCiF, composto por estudiosos de direito tributário, e do movimento VIVA, capitaneado pela Associação dos Agentes Fiscais de Rendas do Estado de São Paulo - AFRESP, que reuniu especialistas tributários com experiência em diferentes áreas da administração tributária.

Em 12 de julho de 2017 foi lançada a primeira consulta pública pelo prazo de 30 dias quando foram apresentadas cerca de 100 sugestões de melhorias. Encerrada a primeira consulta, em 11 de agosto, após a incorporação de parte das sugestões e readequação do projeto, foi aberta uma nova consulta pública em 31 de agosto pelo prazo de uma semana. Desta vez, superada a desconfiança e o impacto inicial da proposta de relacionamento entre o Estado e o cidadão, o número de sugestões cresceu substancialmente sendo reunidas e classificadas em 48 temas diferentes, com propostas de diversos setores e agentes, individuais

Revista Brasileira de Políticas Públicas e Internacionais, v.4, n.1, julho/2019, pp. 195-219. 
MOTA FILHO, Humberto Eustáquio César; MOTA, Eduardo Almeida; LANZ, Luciano Quinto. Agenda e coalizões na aprovação de uma Política Pública Inovadora: o caso da Lei de Conformidade Tributária de São Paulo.

ou de grupos representativos. O Quadro 1 demonstra a evolução das ações formais da SEFAZ/SP.

Quadro 1: Ações formais da Secretaria da Fazenda como Agenda Setter

\begin{tabular}{|c|c|c|c|}
\hline Ação & Data & Ator & Resumo \\
\hline $\begin{array}{l}\text { Apresentação a } \\
\text { grupos específicos } \\
\text { da sociedade civil } \\
\end{array}$ & $\begin{array}{l}\text { Fevereiro a } \\
\text { Julho }\end{array}$ & SEFAZ/SP & $\begin{array}{l}\text { Desconfiança inicial sobre o processo. Diversos } \\
\text { setores da sociedade, academia, comércio, fomento, } \\
\text { terceiro setor, entidades de classe. }\end{array}$ \\
\hline $\begin{array}{l}\begin{array}{l}\text { Sugestões de } \\
\text { aprimoramento }\end{array} \\
\end{array}$ & $\begin{array}{l}\text { Março a } \\
\text { Outubro }\end{array}$ & $\begin{array}{l}\text { Centro de } \\
\text { cidadania } \\
\text { Fiscal }\end{array}$ & $\begin{array}{l}\text { Estudiosos sobre o poder de tributar do Estado que } \\
\text { acrescentaram a perspectiva de melhora no } \\
\text { ambiente de negócios. Participação ativa e } \\
\text { ostensiva. }\end{array}$ \\
\hline $\begin{array}{l}\text { Sugestões de } \\
\text { aprimoramento }\end{array}$ & $\begin{array}{l}\text { Agosto a } \\
\text { Outubro }\end{array}$ & \begin{tabular}{|l} 
Movimento \\
Viva
\end{tabular} & $\begin{array}{l}\text { Aplicadores do Direito Tributário que } \\
\text { acrescentaram melhoras operacionais efetivas. } \\
\text { Participação não ostensiva. }\end{array}$ \\
\hline Consulta pública & $12 / 07 / 2017$ & SEFAZ/SP & $\begin{array}{l}\text { Recebidas mais de } 100 \text { sugestões, principalmente, } \\
\text { dos atores envolvidos desde o início. Participação } \\
\text { ainda tímida do setor privado. }\end{array}$ \\
\hline Consulta pública & $31 / 08 / 2017$ & SEFAZ/SP & $\begin{array}{l}\text { Participação mais ampla da sociedade. Sugestões } \\
\text { agrupadas em } 48 \text { temas. Consolidação do ambiente } \\
\text { de confiança. }\end{array}$ \\
\hline $\begin{array}{l}\text { Encaminhamento } \\
\text { do Projeto de Lei } \\
\text { para a ALESP }\end{array}$ & $16 / 09 / 2017$ & $\begin{array}{l}\text { Governo do } \\
\text { Estado }\end{array}$ & $\begin{array}{l}\text { Apresentação do referencial teórico às comissões } \\
\text { na ALESP. Consolidação do texto legal. Foram } \\
\text { feitas seções de esclarecimento, com produção de } \\
\text { um vídeo institucional e cartilhas com análise do } \\
\text { projeto para os deputados. }\end{array}$ \\
\hline $\begin{array}{l}\text { Apresentação } \\
\text { Emendas }\end{array}$ & $22 / 09 / 2017$ & ALESP & O projeto recebeu 68 emendas. \\
\hline $\begin{array}{l}\text { Emenda } \\
\text { aglutinativa } n^{\circ} 69\end{array}$ & $29 / 03 / 2018$ & ALESP & $\begin{array}{l}\text { Esta emenda aglutinativa foi negociada com os } \\
\text { líderes dos partidos e incorporou a maior parte das } \\
\text { emendas e agendas dos stakeholders. Apresentou } \\
\text { melhorias significativas como: detalhamento dos } \\
\text { benefícios por classificação, tratamento } \\
\text { diferenciado para micro e pequenas empresas, } \\
\text { tratamento para devedores contumazes, definição } \\
\text { de indicadores de desempenho, entre outros. }\end{array}$ \\
\hline $\begin{array}{l}\text { Aprovação da } \\
\text { LC 1320/18 }\end{array}$ & $06 / 04 / 2018$ & ALESP & $\begin{array}{l}\text { Aprovado o texto legal, com a Emenda } \mathrm{n}^{\circ} 69 \text { e as } \\
\text { emendas números } 3 \text { (não estímulo a sonegação), } 4 \\
\text { (limite ao auxílio pecuniário), } 37 \text { (transparência de } \\
\text { parcerias), } 49 \text { (publicação anual de resultados) e } 66 \\
\text { (tratamento de contestações/suspensão de } \\
\text { elegibilidade de créditos). }\end{array}$ \\
\hline
\end{tabular}

Fonte: Elaboração própria.

Revista Brasileira de Políticas Públicas e Internacionais, v.4, n.1, julho/2019, pp. 195-219. 
MOTA FILHO, Humberto Eustáquio César; MOTA, Eduardo Almeida; LANZ, Luciano Quinto. Agenda e coalizões na aprovação de uma Política Pública Inovadora: o caso da Lei de Conformidade Tributária de São Paulo.

Pela análise do Quadro 1, percebe-se as ações da SEFAZ/SP resultaram numa ampliação da participação de atores sociais e no crescimento considerável das sugestões de aprimoramento do texto legal. É possível afirmar que ao longo das apresentações do texto legal e da interação entre os stakeholders, houve uma maior participação, consubstanciada na apresentação de mais sugestões de alterações do texto legal e na incorporação de grande parte dessas sugestões. Essa maior participação pode ser lida como a confirmação da criação de um ambiente confiança entre a SEFAZ/SP e os demais atores sociais, principalmente os contribuintes.

O incremento da participação social contribuiu para a legitimação do texto legal, funcionando como um mecanismo de credibilidade e retroalimentação da proposta de texto e da própria coalização de apoio em si. E tudo isso ocorreu em pouco mais de um ano. Então, esse quadro revela a importância de ações que importem na criação de laços de confiança para o desenvolvimento de cooperação e, consequentemente, para facilitar a formação de coalizões de apoio, corroborando parte da nossa hipótese de trabalho, ao reforçar o papel do agenda setter na equação da formação das alianças.

Preliminarmente, é possível afirmar que ambientes de confiança podem ser estimulados em curtos espaços de tempo, forçando a uma revisão da configuração do problema da confiança. O Quadro 2 traça as avaliações favoráveis (positivas) e desfavoráveis (negativas) ao texto legal nas publicações em sites especializados.

Quadro 2: Análise das principais publicações na imprensa

\begin{tabular}{|l|l|l|l|l|l|}
\hline $\begin{array}{l}\text { Periódico / } \\
\text { site }\end{array}$ & Data & Autor & Efeito & Título & Resumo \\
\hline Jota & $22 / 08 / 2017$ & Aguiar & Positivo & $\begin{array}{l}\text { Transparência e } \\
\text { conformidade: } \\
\text { iniciativa da } \\
\text { Fazenda de SP: } \\
\text { Por uma } \\
\text { mudança do } \\
\text { paradigma atual } \\
\text { da relação fisco- } \\
\text { contribuinte }\end{array}$ & $\begin{array}{l}\text { Projeto guiado por princípios de } \\
\text { governança tributária; compatível } \\
\text { com paradigma de serviço; fomenta } \\
\text { confiança mútua. A partir da } \\
\text { classificação prove benefícios aos } \\
\text { contribuintes. Enfatiza } \\
\text { fundamentação teórica (Alm \& } \\
\text { Trogler, 2012 e OECD, 2015) }\end{array}$ \\
\hline $\begin{array}{l}\text { Consultor } \\
\text { Jurídico }\end{array}$ & $31 / 08 / 2017$ & Mauler & Negativo & $\begin{array}{l}\text { Projeto de lei de } \\
\text { transparência } \\
\text { tributária }\end{array}$ & $\begin{array}{l}\text { Críticas contundentes. A } \\
\text { classificação ostensiva viola o sigilo } \\
\text { fiscal, os benefícios são limitados, o }\end{array}$ \\
\hline
\end{tabular}

Revista Brasileira de Políticas Públicas e Internacionais, v.4, n.1, julho/2019, pp. 195-219. 
MOTA FILHO, Humberto Eustáquio César; MOTA, Eduardo Almeida; LANZ, Luciano Quinto. Agenda e coalizões na aprovação de uma Política Pública Inovadora: o caso da Lei de Conformidade Tributária de São Paulo.

\begin{tabular}{|c|c|c|c|c|c|}
\hline & & & & $\begin{array}{l}\text { camufla sanções } \\
\text { políticas }\end{array}$ & $\begin{array}{l}\text { projeto suprime direitos, atinge } \\
\text { contribuintes de outros estados fora } \\
\text { da competência de São Paulo. } \\
\end{array}$ \\
\hline Jota & $25 / 09 / 2017$ & $\begin{array}{l}\text { Barbosa, } \\
\text { Mascitto } \\
\text { e Paiva }\end{array}$ & Positivo & $\begin{array}{l}\text { A salvação da } \\
\text { relação Fisco e } \\
\text { contribuinte }\end{array}$ & $\begin{array}{l}\text { O modelo repressivo tem mostrado } \\
\text { sinais de esgotamento, muitos } \\
\text { contribuintes não descumprem a } \\
\text { legislação intencionalmente. O } \\
\text { programa propõe criar uma } \\
\text { comunicação entre fisco e } \\
\text { contribuinte, criar uma fase pré- } \\
\text { contenciosa, com mais dialogo e } \\
\text { transparência. }\end{array}$ \\
\hline $\begin{array}{l}\text { Coluna do } \\
\text { Fraga (R7) }\end{array}$ & $18 / 10 / 2017$ & $\begin{array}{l}\text { Mazzitell } \\
\mathrm{i}\end{array}$ & Negativo & $\begin{array}{l}\text { Sindicato critica } \\
\text { forma como } \\
\text { Estado conduz } \\
\text { proposta de } \\
\text { mudança } \\
\text { tributária }\end{array}$ & $\begin{array}{l}\text { Apresenta crítica do Sinafresp } \\
\text { (Sindicato dos Agentes Fiscais de } \\
\text { Renda do Estado de São Paulo) à } \\
\text { condução da proposta, que } \\
\text { privilegiaria grandes contribuintes, } \\
\text { mas é favorável a introdução de } \\
\text { conceitos de conformidade. }\end{array}$ \\
\hline $\begin{array}{l}\text { Consultor } \\
\text { Jurídico }\end{array}$ & 29/10/2017 & $\begin{array}{l}\text { Mota, } \\
\text { Lanz }\end{array}$ & Positivo & $\begin{array}{l}\text { Abordagem do } \\
\text { Estado em São } \\
\text { Paulo vai de } \\
\text { "fisco-policial" } \\
\text { para "fisco- } \\
\text { cidadão" } \\
\end{array}$ & $\begin{array}{l}\text { Explica a fundamentação do projeto } \\
\text { (FMI; Alm \& Trogler), seus } \\
\text { princípios (Conformidade, } \\
\text { consistência e estímulo cadeia de } \\
\text { fornecedores); uso de incentivos e } \\
\text { autorregularização. }\end{array}$ \\
\hline \begin{tabular}{|l} 
Carta \\
Forense
\end{tabular} & $01 / 11 / 2017$ & Silveira & Positivo & $\begin{array}{l}\text { O Projeto de } \\
\text { Conformidade } \\
\text { Tributária }\end{array}$ & $\begin{array}{l}\text { Destaca o contexto de complexidade } \\
\text { em que o projeto será } \\
\text { implementado, com necessidade de } \\
\text { mudança da cultura, de infração para } \\
\text { conformidade e destaca dois pontos } \\
\text { a endereçar: a atualização dos } \\
\text { salários dos fiscais e a participação } \\
\text { nos resultados. Apesar dos riscos, } \\
\text { espera uma melhora no ambiente de } \\
\text { negócios. }\end{array}$ \\
\hline $\begin{array}{l}\text { Consultor } \\
\text { Jurídico }\end{array}$ & $18 / 11 / 2017$ & Almeida & Positivo & \begin{tabular}{|l|} 
Fisco e \\
contribuintes \\
devem parar de \\
se enfrentar e \\
passar a cooperar
\end{tabular} & $\begin{array}{l}\text { Iniciativa inserida em um contexto } \\
\text { mais amplo de compliance tributário } \\
\text { - Fórum sobre Administração } \\
\text { Tributária da OECD (2013) e IN } \\
\text { RFB 1.598/2015. }\end{array}$ \\
\hline
\end{tabular}

Fonte: Elaboração própria.

Pela análise do Quadro 2, evidencia-se que o texto legal não foi objeto de apoio unânime na imprensa especializada. Adicionalmente, revela-se que a percepção da agenda posta pelo texto legal variou, sendo o texto reconhecido por alguns como parte de uma agenda Revista Brasileira de Políticas Públicas e Internacionais, v.4, n.1, julho/2019, pp. 195-219. 
MOTA FILHO, Humberto Eustáquio César; MOTA, Eduardo Almeida; LANZ, Luciano Quinto. Agenda e coalizões na aprovação de uma Política Pública Inovadora: o caso da Lei de Conformidade Tributária de São Paulo.

mais ampla de governança tributária, para outros como um documento violador e restritivo de direitos dos contribuintes e, ainda, visto como parte de uma agenda específica de compliance tributário.

Nesse particular, pode-se cogitar que o agenda setter não teria sido tão efetivo na sua estratégia de comunicação com os stakeholers envolvidos sobre os principais objetivos do projeto, ou apenas reflete uma pluralidade de opiniões próprias de debates públicos. Contudo, no saldo geral, a percepção das principais publicações especializadas foi favorável ao texto legal, o que reforça a capacidade do agenda setter de vincular valores centrais da agenda de compliance como transparência e conformidade ao projeto de lei. Esse tipo de vinculação tende a favorecer a conquista de apoiadores e a formação de coalizões ao texto legal e enfatiza a importância do agenda setter como mobilizador de interesses, ideias e informações capazes de estimular uma maior adesão dos stakeholders, em linha com o modelo de Milner.

\subsection{A interação entre os stakeholders durante a construção da Agenda}

A expectativa dos principais stakeholders pode ser identificada com a análise das publicações e das sugestões de alteração do projeto. A análise dos artigos de opinião e notícias combinada com as sugestões no processo de consulta pública que foram incorporados a versão final do projeto permitem identificar a agenda mínima aceitável de cada interlocutor e definir a agenda consensual mínima necessária para a aprovação do projeto.

Quadro 3: Itens da agenda incorporados ao projeto

\begin{tabular}{|c|c|c|c|c|}
\hline \begin{tabular}{|l} 
Item da \\
agenda
\end{tabular} & \begin{tabular}{|l} 
Stakeholder \\
interessado
\end{tabular} & $\begin{array}{l}\text { Etapa da } \\
\text { incorporação }\end{array}$ & Efeito & Resumo \\
\hline $\begin{array}{l}\text { Aumento de } \\
\text { arrecadação }\end{array}$ & Governo & \begin{tabular}{|l} 
Incorporado \\
como \\
estratégia do \\
Programa
\end{tabular} & $\begin{array}{l}\text { Incorporado } \\
\text { na estratégia } \\
\text { como } \\
\text { princípio, } \\
\text { Artigo } 1^{\circ} \text { da } \\
\text { LC } \\
\end{array}$ & $\begin{array}{l}\text { A estratégia busca o aumento da } \\
\text { base de contribuintes regulares } \\
\text { pelo incentivo à auto- } \\
\text { regularização e incentivos à } \\
\text { operação com uma cadeia de } \\
\text { fornecedores regulares. }\end{array}$ \\
\hline $\begin{array}{l}\text { Racionalizar o } \\
\text { contencioso } \\
\text { administrativo } \\
\text { tributário }\end{array}$ & CECiF & $\begin{array}{l}\text { Incorporado } \\
\text { como } \\
\text { estratégia } \\
\text { inicial do } \\
\text { programa }\end{array}$ & $\begin{array}{l}\text { Incorporado } \\
\text { na estratégia } \\
\text { como } \\
\text { princípio, } \\
\text { Artigos } 1^{\circ}\end{array}$ & $\begin{array}{l}\text { Ao incentivar a } \\
\text { autorregularização com } \\
\text { orientação e oportunidade de } \\
\text { correção dos erros antes da } \\
\text { lavratura de auto de infração e }\end{array}$ \\
\hline
\end{tabular}

Revista Brasileira de Políticas Públicas e Internacionais, v.4, n.1, julho/2019, pp. 195-219. 
MOTA FILHO, Humberto Eustáquio César; MOTA, Eduardo Almeida; LANZ, Luciano Quinto. Agenda e coalizões na aprovação de uma Política Pública Inovadora: o caso da Lei de Conformidade Tributária de São Paulo.

\begin{tabular}{|c|c|c|c|c|}
\hline & & & $\begin{array}{l}14 \text { e } 16 \text { da } \\
\text { LC }\end{array}$ & $\begin{array}{l}\text { multa, evita o contencioso } \\
\text { administrativo. A diminuição do } \\
\text { número de processos facilitará o } \\
\text { investimento na melhora da } \\
\text { qualidade dos julgamentos. }\end{array}$ \\
\hline $\begin{array}{l}\text { Redução de } \\
\text { despesas e } \\
\text { custos de } \\
\text { conformidade, } \\
\text { diminuição da } \\
\text { concorrência } \\
\text { desleal }\end{array}$ & FIESP & $\begin{array}{l}\text { Aperfeiçoame } \\
\text { nto do Projeto } \\
\text { de Lei, } \\
\text { incorporado } \\
\text { antes da } \\
\text { primeira } \\
\text { consulta }\end{array}$ & $\begin{array}{l}\text { Incorporado } \\
\text { na estratégia } \\
\text { como } \\
\text { princípio, } \\
\text { Artigos } 1^{\circ} \text { e } \\
5^{\circ} \text { da LC. }\end{array}$ & $\begin{array}{l}\text { A complexidade do sistema } \\
\text { tributário atual demanda grandes } \\
\text { investimentos em setores } \\
\text { estranhos ao negócio principal } \\
\text { dos contribuintes. Este item foi } \\
\text { incorporado com a simplificação } \\
\text { de obrigações acessórias. A } \\
\text { concorrência desleal será } \\
\text { combatida com a incorporação da } \\
\text { cadeia de fornecedores na } \\
\text { avaliação dos contribuintes para a } \\
\text { concessão de benefícios. }\end{array}$ \\
\hline $\begin{array}{l}\text { O tratamento } \\
\text { para casos de } \\
\text { contestações }\end{array}$ & $\begin{array}{l}\text { ACSP e } \\
\text { Imprensa } \\
\text { Especializada }\end{array}$ & $\begin{array}{l}\text { Entre a } \\
\text { primeira e } \\
\text { segunda } \\
\text { consulta } \\
\text { pública } \\
\end{array}$ & Artigo $6^{\circ}$ & $\begin{array}{l}\text { Inserção legal da possibilidade de } \\
\text { oposição à publicidade da } \\
\text { classificação do contribuinte. }\end{array}$ \\
\hline $\begin{array}{l}\text { Maior } \\
\text { flexibilidade } \\
\text { para as faixas } \\
\text { de risco }\end{array}$ & SEFAZ/SP & $\begin{array}{l}\text { Entre a } \\
\text { primeira e } \\
\text { segunda } \\
\text { consulta } \\
\text { pública } \\
\end{array}$ & Artigo $7^{\circ}$ & $\begin{array}{l}\text { Melhorar a operacionalidade } \\
\text { técnica do programa. }\end{array}$ \\
\hline $\begin{array}{l}\text { Estabelecer } \\
\text { canal de } \\
\text { comunicação } \\
\text { oficial entre } \\
\text { Estado e } \\
\text { Contribuinte }\end{array}$ & CODECON & $\begin{array}{l}\text { Entre a } \\
\text { primeira e } \\
\text { segunda } \\
\text { consulta } \\
\text { pública }\end{array}$ & $\begin{array}{l}\text { Incorporado } \\
\text { no Artigo } 3^{\circ} \\
\text { da LC }\end{array}$ & $\begin{array}{l}\text { Apresentação de relatórios } \\
\text { semestrais ao CODECON sobre o } \\
\text { desenvolvimento do projeto. }\end{array}$ \\
\hline $\begin{array}{l}\text { Incentivos ao } \\
\text { desenvolvimen } \\
\text { to do } \\
\text { Programa }\end{array}$ & $\begin{array}{l}\text { AFRESP/SINA } \\
\text { FRESP }\end{array}$ & $\begin{array}{l}\text { Apresentação } \\
\text { final do } \\
\text { projeto para } \\
\text { votação }\end{array}$ & $\begin{array}{l}\text { Capítulo VII } \\
\text { da LC }\end{array}$ & $\begin{array}{l}\text { Incorporação de auxílio } \\
\text { pecuniário atrelado ao } \\
\text { cumprimento de metas de } \\
\text { desempenho com foco na } \\
\text { autorregularização. } \\
\end{array}$ \\
\hline $\begin{array}{l}\text { Tratamento } \\
\text { para } \\
\text { fornecedores } \\
\text { de outros } \\
\text { estados }\end{array}$ & $\begin{array}{l}\text { FECOMERCIO } \\
\text { /ACSP/SEFAZ/ } \\
\text { SP }\end{array}$ & $\begin{array}{l}\text { Apresentação } \\
\text { final do } \\
\text { projeto para } \\
\text { votação }\end{array}$ & Artigo 10 & $\begin{array}{l}\text { Tratamento isonômico a todos os } \\
\text { fornecedores aplicando-se o } \\
\text { mesmo regramento para os casos } \\
\text { de substituição tributária. }\end{array}$ \\
\hline
\end{tabular}

Fonte: Elaboração própria.

Revista Brasileira de Políticas Públicas e Internacionais, v.4, n.1, julho/2019, pp. 195-219. 
MOTA FILHO, Humberto Eustáquio César; MOTA, Eduardo Almeida; LANZ, Luciano Quinto. Agenda e coalizões na aprovação de uma Política Pública Inovadora: o caso da Lei de Conformidade Tributária de São Paulo.

Pela análise do Quadro 3, revela-se mais claramente a estratégia da SEFAZ/SP para favorecer o avanço do texto legal não consistiu apenas em fornecer os corretos incentivos aos diferentes stakeholders. Com uma posição institucional de relevância e a vantagem inicial de ser o proponente da agenda, a SEFAZ/SP adotou uma postura não só de agenda setter, mas valorizou a incorporação de sugestões dos stakeholders desde o início das discussões. Essa postura contribui para uma colaboração baseada na confiança, ao propiciar um interação que se desenvolve ao longo do período entre as consultas públicas e uma interação direcionada com cada stakeholders, ao realizar também rodadas de negociações segmentadas, de modo a calibrar corretamente os incentivos que poderiam ser oferecidos para angariar os apoios dos atores sociais, abordando o problema da confiança em etapas e discutindo interesses subjacentes em vez de negociar posições fixas.

Para tanto, foi necessário conhecer as preferências de cada um dos stakeholders, que estiveram em linha com os interesses do modelo de Shepsle, mas que não seriam alinhadas, caso não houvesse o tempo e as interações necessárias para a construção dos laços de confiança que possibilitou a cooperação dos atores até o final dos debates. Pode-se afirmar que não só a posição institucional relevante, nem o oferecimento dos incentivos corretos seriam suficientes caso não houvesse a dinâmica de debates e incorporação de sugestões alinhavada pela SEFAZ/SP e aceita pelos atores sociais.

\section{Replicando a Estratégia e Refinando o Modelo}

\subsection{Proposta de refinamentos nos modelos de formação de agenda e de coalizões}

Considerando a análise do processo de discussão e construção de apoios para a aprovação da lei, podemos propor modelos/quadro de referência para a formação de agenda e coalizões para aprovação de propostas legislativas inovadoras, não restritos aos esquemas teóricos explicativos do alinhamento dos interesses dos stakeholders pelo oferecimento dos incentivos, nem à identificação dos empreendedores legislativos ou do agenda setter e apontar sua relevância institucional para o encaminhamento das questões, incluindo a composição de

Revista Brasileira de Políticas Públicas e Internacionais, v.4, n.1, julho/2019, pp. 195-219. 
MOTA FILHO, Humberto Eustáquio César; MOTA, Eduardo Almeida; LANZ, Luciano Quinto. Agenda e coalizões na aprovação de uma Política Pública Inovadora: o caso da Lei de Conformidade Tributária de São Paulo.

formas de interação indutoras de uma cooperação entre os atores públicos e privados, baseada na criação ou estreitamento dos laços de confiança.

Quadro 4: Proposta de Modelos de Formação de Agenda e de Coalizões

\begin{tabular}{|c|c|c|}
\hline Ação proposta & Experiência de São Paulo & Fundamentação \\
\hline $\begin{array}{l}\text { Planejamento da } \\
\text { iniciativa como } \\
\text { política pública }\end{array}$ & $\begin{array}{l}\text { Agenda clara, com etapas definidas: } \\
\text { apresentações internas; melhoria de } \\
\text { cadastros e bancos de dados; } \\
\text { consultas públicas (PLC 25/2017) }\end{array}$ & $\begin{array}{l}\text { Definição de agenda, elaboração, } \\
\text { formulação, implementação, } \\
\text { execução, acompanhamento e } \\
\text { avaliação (Saravia, 2006). }\end{array}$ \\
\hline $\begin{array}{l}\text { Uso de agenda } \\
\text { setters and policy } \\
\text { makers }\end{array}$ & $\begin{array}{l}\text { Palestras e publicações de } \\
\text { especialistas da SEFAZ/SP; } \\
\text { alinhamento com a academia e } \\
\text { formadores de opinião }\end{array}$ & $\begin{array}{l}\text { Utilização de formadores de agenda e } \\
\text { formuladores de políticas públicas } \\
\text { (Kingdon, 2011) }\end{array}$ \\
\hline $\begin{array}{l}\text { Formação de } \\
\text { coalizões }\end{array}$ & $\begin{array}{l}\text { Entidades empresariais } \\
\text { (previsibilidade, uso de incentivos, } \\
\text { diminuição da discricionariedade dos } \\
\text { agentes); }\end{array}$ & $\begin{array}{l}\text { Formação de coalizões de interesses } \\
\text { (ROE, 2013) }\end{array}$ \\
\hline $\begin{array}{l}\text { Mudança de } \\
\text { agenda } \\
\text { (capacidade de } \\
\text { adaptação) }\end{array}$ & $\begin{array}{l}\text { Entidades de fiscais (criação de } \\
\text { incentivos pecuniários a adesão ao } \\
\text { projeto). }\end{array}$ & $\begin{array}{l}\text { Interação entre ideias, interesses e } \\
\text { informações (Milner, 1998); } \\
\text { Mudanças nas agendas (Mota Filho, } \\
\text { 2016) }\end{array}$ \\
\hline $\begin{array}{l}\text { Transparência e } \\
\text { compartilhamento } \\
\text { de informações }\end{array}$ & $\begin{array}{l}\text { Classificação ostensiva de } \\
\text { contribuintes. }\end{array}$ & $\begin{array}{l}\text { Colaboração baseada na confiança } \\
\text { (Arnstein,1969; Ovanessoff, Plastino } \\
\text { e Faleiro, 2015). }\end{array}$ \\
\hline $\begin{array}{l}\text { Segmentação de } \\
\text { partes interessadas } \\
\text { (stakeholders) }\end{array}$ & $\begin{array}{l}\text { Por público alvo: cidadão, empresa e } \\
\text { servidor. Segmentação por critérios de } \\
\text { conformidade: adimplência, aderência } \\
\text { da escrituração e conformidade dos } \\
\text { fornecedores. Vai além da } \\
\text { segmentação por porte. }\end{array}$ & $\begin{array}{l}\text { Gradualismo e colaboração em etapas } \\
\text { (Axelrod, 1984, e Ovanessoff, } \\
\text { Plastino e Faleiro, 2015). }\end{array}$ \\
\hline $\begin{array}{l}\text { Diálogo e criação } \\
\text { de relacionamento } \\
\text { com a sociedade }\end{array}$ & $\begin{array}{l}\text { Notícias no portal da SEFAZ/SP, } \\
\text { consulta pública, apresentação para } \\
\text { entidades empresariais, discussão com } \\
\text { academia e formadores de opinião. }\end{array}$ & $\begin{array}{l}\text { Interações repetidas ao longo do } \\
\text { tempo (Axelrod, } 1984 \text { e Ovanessoff, } \\
\text { Plastino e Faleiro, 2015). }\end{array}$ \\
\hline
\end{tabular}

Fonte: Elaboração própria.

Pela análise do Quadro 4, é esclarecido como o Modelo de Agenda e Formação de Coalizões proposto reúne características capazes de explicar os fatores que possibilitaram a aprovação da Lei "Nos Conformes" em pouco mais de um ano, desde o início dos debates.

Assim, esse modelo: inclui em seu planejamento as etapas de construção da agenda de uma política pública incorporando o conceito de agende setters sem necessariamente atribuir,

Revista Brasileira de Políticas Públicas e Internacionais, v.4, n.1, julho/2019, pp. 195-219. 
MOTA FILHO, Humberto Eustáquio César; MOTA, Eduardo Almeida; LANZ, Luciano Quinto. Agenda e coalizões na aprovação de uma Política Pública Inovadora: o caso da Lei de Conformidade Tributária de São Paulo.

ab initio, um peso determinante as instituições, aos atores racionais, aos interesses e as ideias. Igualmente reconhece a importância dos defensores das iniciativas legislativas em sua capacidade de convencimento e no empenho de sua credibilidade para o avanço de agendas públicas, refinando o Modelo de Kingdon ao relativizar a importância desse ator com outros fatores e atores. Mais ainda, admite o poder explicativo da formação de coalizão de interesses para o fortalecimento da agenda e, por outro lado acrescenta a essa explicação os achados sobre a importância da capacidade de flexibilização da agenda via interação entre ideias, interesses e informações, conforme Milner. Expõe as evidências sobre a força explicativa da cooperação pela interação, a partir de Axelrod, como forma de criar e consolidar laços de confiança que permitem reforçar a coalizão e reduzir o tempo para o avanço das propostas legais, conforme Ovanessoff, Plastino e Faleiro. Ao fortalecer o relacionamento com a sociedade civil organizada e gerar participação social efetiva, como proposto por Arnstein, traz legitimidade ao projeto de lei, reforça os laços de confiança e a coalização formada.

Os laços de confiança são um mecanismo de retroalimentação da cooperação, tendo a SEFAZ/SP o mérito de ter dado o impulso inicial que permitiu o seu funcionamento, ainda que precariamente, e ter sustentado, com a dinâmica de interações, a credibilidade do debate da agenda perante os stakeholders, consolidando essa cooperação.

\section{Conclusões}

A análise das publicações na imprensa e das apresentações e encontros com entidades da sociedade civil e com entidades empresariais demonstram que a SEFAZ/SP obteve sucesso em formar coalizões favoráveis ao projeto ao atuar como agenda setter no caso da Lei "Nos Conformes".

Entretanto, esse sucesso não é explicado apenas pela posição institucional de destaque da SEFAZ/SP e seu protagonismo no avanço do texto legal, nem pelo alinhamento de interesses das burocracias com os interesses dos contribuintes e empresários, a partir do modelo teórico do ator racional. Os resultados indicam que a SEFAZ/SP conseguiu formar uma coalização, por meio do diálogo e da criação de laços de confiança entre entidades empresariais, instituições políticas, sociedade civil e entidades representativas dos fiscais, o que

Revista Brasileira de Políticas Públicas e Internacionais, v.4, n.1, julho/2019, pp. 195-219. 
MOTA FILHO, Humberto Eustáquio César; MOTA, Eduardo Almeida; LANZ, Luciano Quinto. Agenda e coalizões na aprovação de uma Política Pública Inovadora: o caso da Lei de Conformidade Tributária de São Paulo.

levou a aprovação de um programa significativamente melhorado em relação à proposta original em um curto espaço de tempo para matérias legislativas.

O estudo permitiu construir um quadro de referência que pode ser testado em outros casos que envolvam o avanço de agendas e a formação de coalizões para aprovação de propostas legislativa inovadoras.

Nesse sentido, relativizou-se a importância do empreendedor legislativo na figura do agenda setter e do modelo do ator racional com preferências fixas e interesses definidos, $a$ priori, e atribui-se um peso significativo as estratégias de colaboração e criação de laços de confiança num modelo que atribui a participação social e as interações público-privadas papel central na explicação do sucesso de iniciativas legislativas inovadoras e sua aprovação em curto espaço de tempo, ao estabelecer um tipo específico de interação em uma rede de stakeholders.

Para validar essas conclusões sugere-se a replicação do modelo para outros casos, em novas pesquisas, envolvendo tanto casos de aprovações como casos de não aprovações de projetos legislativos inovadores, a fim de estabelecer uma forma de controle sobre as principais variáveis consideráveis e ratificar ou não os resultados obtidos nesse caso e o efetivo impacto da cooperação entre stakeholders a partir da observação de casos não similares.

Por fim, outras investigações podem avançar na compreensão do efeito da criação dos laços de confiança no tempo de tramitação de iniciativas legislativas. Nesse sentido, seria oportuno controlar a variável do tempo de tramitação dos textos legais inovadores aprovados em relação a criação ou não de laços de confiança, a fim de averiguar o impacto da cooperação entre stakeholders nos resultados das agendas públicas legislativas, a partir de casos similares.

\section{Referências}

Aguiar, L. I. (2017) Transparência e conformidade: iniciativa da Fazenda de SP: Por uma mudança do paradigma atual da relação fisco-contribuinte. Jota. Disponível em $<$ http://www.jota.info/opiniao-e-analise/artigos/transparencia-e-conformidade-iniciativa-dafazenda-de-sp-21082017> Acesso em: 12 fev. 2018.

Alm, J., Martinez-Vazquez, J., \& Torgler, B. (2010). Developing Alternative Frameworks for Explaining Tax Compliance. New York: Routledge.

Revista Brasileira de Políticas Públicas e Internacionais, v.4, n.1, julho/2019, pp. 195-219. 
MOTA FILHO, Humberto Eustáquio César; MOTA, Eduardo Almeida; LANZ, Luciano Quinto. Agenda e coalizões na aprovação de uma Política Pública Inovadora: o caso da Lei de Conformidade Tributária de São Paulo.

Almeida, C. O. (2017). Fisco e contribuintes devem parar de se enfrentar e passar a cooperar. Consultor Jurídico. Disponível em <https://www.conjur.com.br/2017-nov-18/carlos-almeidafisco-contribuinte-cooperar> Acesso em: 12 fev. 2018.

Arnstein, Sherry R. (1969). A ladder of citizen participation. Journal of the American Institute of Planners, 35 (4), p. 216-224.

Axelrod, Robert. (1984). The Evolution of Cooperation. New York: Basic Books.

Barbosa, Luiz R. P; Mascitto, Andréa; Paiva, Mariana M. A. (2017) A salvação da relação Fisco e contribuinte. Jota. Disponível em https://www.jota.info/paywall?redirect_to=//www.jota. info/opiniao-e-analise/artigos/a-salvacao-da-relacao-fisco-e-contribuinte-25092017> Acesso em: 12 fev. 2018.

Bird, R. (2010). Smart Tax Administration. Economic Premise. The World Bank - Economic Premise, p. 1 - 5.

Capella, A. C. N.; Brasil, F. G. (2015). Análise de políticas públicas: uma revisão da literatura sobre o papel dos subsistemas, comunidades e redes. Novos estud. - CEBRAP, São Paulo, 101, p. 57-76. Disponível em <http://www.scielo.br/scielo.php?pid=S010133002015000100057 \&script=sci_abstract\&tlng=pt $>$ Acesso em: 12 fev. 2018.

Catlett, Cynthia; Saud, Salim. (2016). Compliance. Rio de Janeiro: Editora FGV.

Confederação Nacional Da Indústria (CNI). (2017). Retratos da Sociedade Brasileira: Confiança Interpessoal, ISSN 2317-7012, 6 (39), Julho.

Elman, Colin. (2005). Explanatory typologies in qualitative studies of international politics. International Organization, 59 (2), p. 293-326.

Freeman, J. Leiper. (1955). The political process: executive-bureau-legislative committee relations. Nova York: Random House.

Fung, Archon; Wright, Erik Olin (2003), Deepening Democracy: Institutional Innovations in Empowered Participatory Governance. London: Verso.

Garcia-Zamor, Jean-Claude. (2003). Workplace Spirituality and Organizational Performance. Public Administration Review, 63, (May/June), 355-363.

Instituto Brasileiro De Governança Corporativa. (2017). Compliance à luz da governança corporativa. São Paulo, SP: IBGC.

Revista Brasileira de Políticas Públicas e Internacionais, v.4, n.1, julho/2019, pp. 195-219. 
MOTA FILHO, Humberto Eustáquio César; MOTA, Eduardo Almeida; LANZ, Luciano Quinto. Agenda e coalizões na aprovação de uma Política Pública Inovadora: o caso da Lei de Conformidade Tributária de São Paulo.

FMI. (2016). Corruption: Costs and Mitigating Strategies. Washington: International Monetary Fund.

Kim, Ho-Seob. (2001). Organizational Structure and Ethics Attitudes of Public Officials. Public Integrity, Winter, 3, 69-86.

Kingdon, John W. (2011). Agendas, Alternatives, and Public Policies. 2nd. ed. Longman, Boston.

Mauler, I. (2017). Projeto de lei de transparência tributária camufla sanções políticas. Consultor Jurídico.

Mazzitelli, Fábio. (2017). Sindicato critica forma como Estado conduz proposta de mudança tributária. Coluna do Fraga, R7. 18 out. Disponível em <https://noticias.r7.com/prisma/colunado-fraga/sindicato-critica-forma-como-estado-conduz-proposta-de-mudanca-tributaria02012018> Acesso em: 12 fev. 2018.

Menzel, Donald C. (2005). Research on Ethics and Integrity in Governance: A Review and Assessment, Public Integrity, 7(2), 147-168.

Milner, Helen V. (1997). Interests, institutions and information: Domestic Politics and International Relations. Princeton: Princeton University Press.

Mota, Eduardo Almeida; Lanz, Luciano Quinto. (2017). Abordagem do Estado em São Paulo vai de "fisco-policial" para "fisco-cidadão". Consultor Jurídico, 27 out. Disponível em https://www.conjur.com.br/2017-out-29/opiniao-fisco-policial-sao-paulo-fisco-cidadao Acesso em: 12 fev. 2018.

Mota Filho, Humberto. (2016). As escolhas políticas de integração nos casos do Mercosul e da ALCA. Gramma.

NUNES, E. D. O. (1997). A gramática política do Brasil: clientelismo, corporativismo e insulamento burocrático. Rio de Janeiro: Garamond.

Olson, Mancur. (1965). The Logic of Collective Action. Harvard University Press.

Ovanessoff, Armen; Plastino, Eduardo; Faleiro, Flaviano. (2015). Por que o Brasil precisa aprender a confiar na inovação colaborativa. Accenture.

Rego, Armenio, Claudia S. Sarrico, Jose Manuel Moreira. (2005). Trust in Portuguese Public Authorities. Public Integrity.

Revista Brasileira de Políticas Públicas e Internacionais, v.4, n.1, julho/2019, pp. 195-219. 
MOTA FILHO, Humberto Eustáquio César; MOTA, Eduardo Almeida; LANZ, Luciano Quinto. Agenda e coalizões na aprovação de uma Política Pública Inovadora: o caso da Lei de Conformidade Tributária de São Paulo.

Rhodes, R. A.W. (2008). Policy network analysis. In: Moran, M.; Rein, M.; Goodin, R. E. (eds.). The Oxford handbook of public policy. Oxford: Oxford University Press.

Roth Deubel, A. N. (2006). Políticas públicas: formulación, implementación y evaluación, Colômbia: Ediciones Aurora.

Saarniit, L. (2005). A Public Service Code of Ethics Applied in a Transitional Settings. The Case of Estonia. Public Integrity, Winter, 6 (1), p. 49-63.

Sabatier, P., Jenkins-Smith, H. (1993). The Advocacy Coalition Framework: Assessment, Revisions and Implications for Scholars and Practitioners." In Sabatier, P.; Jenkins-Smith, H. Policy Change and Learning: An Advocacy Coalition Approach. Boulder.

Saravia, E. (2006). Introdução à Teoria da Política Pública. In E. Saravia, Ferrarezi, \& E. (org), Políticas Públicas - Coletânea - Volume 1. Brasília: ENAP. Disponível em <http://repositorio.enap.gov.br/handle/1/3132> Acesso em: 12 fev. 2018.

Shepsle, Kenneth A. (2010). Analysing politics: rationality, behavior, and institutions. 2nd ed. W.W. Norton \& Company, New York.

True, James L.; Jones, Bryan D.; Baumgartner, Frank R. (1999). Punctuated equilibrium theory. Theories of the policy process, p. 175-202.

Tsebelis, George. (2002). Veto Players: How Political Institutions Work. Princeton, NJ: Princeton University Press.

Windhoff-Héritier, Adrienne. (1991). Institutions, Interests and Political Choice. In: Czada, Roland M.; Windhoff-Héritier, A. Political Choice: institutions, rules, and the limits of rationality. p, 27-52.

Yin, Robert K. (2014). Case study research: Design and methods, Sage Publications.

Revista Brasileira de Políticas Públicas e Internacionais, v.4, n.1, julho/2019, pp. 195-219. 